\title{
Composição nutricional de geleias de umbu-cajá durante estocagem em temperatura ambiente
}

\author{
Nutritional composition of Imbu-Cajá jellies during room temperature storage
}

\author{
Emanuel Neto Alves de Oliveira ${ }^{1 *}$, Dyego da Costa Santos ${ }^{2}$, Ana Paula Trindade Rocha ${ }^{3}$, Josivanda Palmeira Gomes ${ }^{3}$, \\ Regilane Marques Feitosa ${ }^{3}$, Bruno Fonsêca Feitosa ${ }^{4}$ \\ 1 Instituto Federal de Educação, Ciência e Tecnologia do Rio Grande do Norte (IFRN), Departamento de Tecnologia de Alimentos, Campus Pau dos \\ Ferros, Pau dos Ferros/RN - Brasil \\ 2 Instituto Federal de Educação, Ciência e Tecnologia do Acre, Xapuri/AC - Brasil \\ ${ }^{3}$ Universidade Federal de Campina Grande (UFCG), Departamento de Engenharia Agrícola, Campina Grande/PB - Brasil \\ ${ }^{4}$ Universidade Federal de Campina Grande (UFCG), Departamento de Engenharia de Alimentos, Pombal/PB - Brasil
}

\section{${ }^{*}$ Corresponding Author}

Emanuel Neto Alves de Oliveira, Instituto Federal de Educação, Ciência e Tecnologia do Rio Grande do Norte (IFRN), Departamento de Tecnologia de Alimentos, Campus Pau dos Ferros, BR-405, km 154, s/n, CEP: 59900-000, Pau dos Ferros/RN - Brasil, e-mail: emanuel.oliveira16@gmail.com

Cite as: Nutritional composition of Imbu-Cajá jellies during room temperature storage. Braz. J. Food Technol., v. 21, e2018033, 2018.

Received: Nov. 04, 2017; Accepted: May 03, 2018

\section{Resumo}

Objetivou-se, com o estudo, avaliar a composição nutricional de geleias de umbu-cajá elaboradas com sacarose e aspartame, durante estocagem em temperatura ambiente. Foram elaboradas as formulações a partir de uma mistura com quatro partes de água para seis partes de polpa, pectina e açúcar cristal, nas formulações convencionais, e aspartame nas formulações dietéticas. As formulações foram aquecidas e concentradas até atingir aproximadamente $63^{\circ}$ Brix (geleias convencionais com açúcar) e 12,5B Brix (geleias dietéticas com aspartame), com posterior acondicionamento em potes de vidro transparentes e mantidos por 180 dias em condições ambientais, com análise da composição nutricional no tempo inicial (após processamento) e a cada 30 dias de armazenamento. Verificou-se que as geleias dietéticas apresentaram boa estabilidade nutricional durante o período de estocagem, não sendo detectadas alterações significativas nos valores de cinzas, teor de água, proteínas, valor calórico, carboidratos e açúcares totais. Quanto às geleias convencionais, constatou-se que os 180 dias de armazenamento promoveram aumentos significativos para carboidratos, nas calorias e nos açúcares redutores, e reduções significativas para teor de água, açúcares totais e açúcares não redutores, enquanto que os valores de cinzas se mantiveram estatisticamente estáveis, assim como os de proteínas.

Palavras-chave: Spondias spp.; Fruto tropical; Produto dietético; Aspartame; Valor calórico; Estabilidade físico-química.

\section{Abstract}

The objective of this study was to evaluate the nutritional composition of imbu-cajá jellies made with sucrose and aspartame during room temperature storage. The formulations were prepared from a mixture of 4 parts of water to 6 parts of pulp, pectin and crystal sugar, in conventional formulations, and aspartame in the dietary formulations. The formulations were heated and concentrated to approximately $63^{\circ}$ Brix (conventional jellies with sugar) and $12.5^{\circ}$ Brix (dietary jellies with aspartame), then packaged in transparent glass jars, and held for 180 days under ambient conditions, with an analysis of the nutritional composition at zero time (after processing) and after every 30 days of storage. It was verified that the dietary jellies showed good nutritional stability during the storage period, and no significant changes were detected in the values for ash, water content, proteins, caloric value, carbohydrates and total sugars. As for the conventional jellies, it was found that the 180 days of storage promoted significant increases in carbohydrates, calories and reducing sugars, and significant reductions in the water content, total sugars and non-reducing sugars, while the ash values remained statistically stable as also those of the proteins.

Keywords: Spondias spp.; Tropical fruit; Dietary product; Aspartame; Caloric value; Physicochemical stability. 


\section{Introdução}

Na economia de mercados dinâmicos, o processamento de novos produtos se torna fator essencial para um bom andamento da empresa, especialmente para as de alimentos, que frequentemente necessitam inovar, a fim de permanecer à frente da concorrência. Atualmente, a expectativa de consumidores quanto às novidades na área alimentícia e a redução da lealdade às marcas tradicionais fazem o mercado de alimentos ainda mais competitivo (DAMIANI et al., 2012).

Nesse contexto, a utilização de frutas da região semiárida brasileira, ainda pouco exploradas comercialmente, torna-se ponto-chave para a criação de produtos. A umbu-cajá (Spondias spp.), por possuir sabor e aroma agradáveis, aparência atrativa e valor nutritivo considerável (LIMA et al., 2002), é uma das frutas da região que podem ser utilizadas na elaboração de inovações para o setor alimentício, pois, além de incorporar valor econômico à fruta, ainda atenderia à expectativa de consumidores quanto ao lançamento de inovações no setor alimentício. Como alternativa de processamento, há a possibilidade de elaboração de geleias convencionais e dietéticas.

O desenvolvimento de produtos alimentícios com baixo valor calórico, por muitos anos, foi direcionado a uma parte da população que possuía problemas de saúde, como a diabetes, e tinha restrição de consumo de açúcar. No entanto, com o passar dos anos, a população, frente aos problemas de saúde provocados pelo consumo exagerado do açúcar e em busca de uma vida mais saudável, passa a consumir produtos dietéticos antes consumidos apenas por pessoas que seguiam recomendações médicas, tornando-se, assim, hábito na mesa do brasileiro o seu consumo. Uma vez que muitos produtos dietéticos já competem em qualidade com alimentos desenvolvidos com apenas açúcar (PRATI et al., 2009), tornam-se necessários estudos com o emprego de edulcorantes em geleias (YUYAMA et al., 2008), a fim de popularizar a categoria de baixo valor calórico no setor de conservas de frutas, como já ocorre em outros setores alimentícios.

No mercado alimentício, pode ser encontrada uma série de edulcorantes utilizados para o processamento de produtos dietéticos ou com valor calórico reduzido, cada um com características específicas de intensidade de doçura, permanência do sabor doce e existência ou não de gosto residual. Dentre os produtos adoçantes permitidos pela legislação brasileira (BRASIL, 2008), tem-se o aspartame. De acordo com Cardello et al. (2000), a popularização do aspartame deve-se ao seu sabor, que é quase igual ao apresentado pela sacarose. Mediante pesquisas realizadas, pode-se constatar que, em uma solução de sacarose a 10\%, o aspartame foi o edulcorante que se apresentou mais próximo à sua equivalência de doçura.
Na produção de geleias dietéticas, além de edulcorantes, é utilizada pectina do tipo BTM (Baixo Teor de Metoxilação), capaz de gelificar na presença de íons metálicos bivalentes, geralmente o cálcio, não sendo necessário a adição de açúcares (MESQUITA et al., 2013; NGOUÉMAZONG et al., 2012). Já na formulação de geleias convencionais, é utilizada pectina do tipo ATM (Alto Teor de Metoxilação), necessitando de teores de sólidos solúveis superiores a 50\% (BARCIA et al., 2010).

Apesar de o processamento de geleias ser uma possibilidade de estender o tempo de consumo e o período de conservação de frutas, o armazenamento em longo prazo pode acelerar reações de degradação de alguns componentes nutricionais, tornando-se necessários estudos da estabilidade nutricional dos produtos. Na literatura, podem ser encontradas várias pesquisas abordando a estabilidade durante o armazenamento de geleias convencionais e com baixo valor calórico (light ou diet) de diversas frutas, tais como: geleia diet de goiaba (MESQUITA et al., 2013); geleias convencionais de buriti (CELESTINO, 2013); geleia convencional e light de araticum (ARÉVALO-PINEDO et al., 2013); geleia convencional e light de maná cubiu (FURLANETO et al., 2015); geleia mista convencional de melão e acerola (PAIVA et al., 2015); geleias convencionais de cajá (MARTINS et al., 2015); geleias convencionais de amora-preta (CARNEIRO et al., 2016), e geleias convencionais de murici (MONTEIRO e PIRES, 2016).

Ante o exposto, objetivou-se, com a pesquisa, estudar as características nutricionais de geleias elaboradas com sacarose e aspartame de umbu-cajá estocadas por 180 dias, em temperatura ambiente.

\section{Material e métodos}

Para a elaboração das geleias, foi utilizada a polpa diluída (quatro partes de água para seis partes de polpa) extraída de frutos maduros de umbu-cajá. A polpa diluída teve o pH corrigido para 3,2 com bicarbonato de sódio.

Para as formulações das geleias convencionais, foram utilizadas sacarose comercial e pectina ATM (Alto Teor de Metoxilação). Na formulação das geleias dietéticas, foram utilizados aspartame, pectina BTM (Baixo Teor de Metoxilação) e, para ajudar na gelificação, cloreto de cálcio conforme quantidades apresentadas na Tabela 1. Todas as concentrações dos ingredientes utilizados na elaboração das geleias seguiram o estabelecido pela legislação brasileira (BRASIL, 1978, 2008, 2009).

Após a formulação das geleias, as misturas foram submetidas a aquecimento e concentradas até que as formulações de geleias convencionais atingissem $63^{\circ}$ Brix e as formulações dietéticas, $12,5^{\circ}$ Brix, com posterior acondicionamento em potes de vidro transparentes com tampa metálica (185 mL). As geleias prontas foram mantidas por 180 dias em temperatura ambiente média de $23,25^{\circ} \mathrm{C}$ e umidade relativa de $81 \%$. 
Tabela 1. Formulações de geleias convencionais e dietéticas de umbu-cajá

\begin{tabular}{|c|c|c|c|c|c|c|}
\hline Geleia & $\begin{array}{c}\text { Polpa diluída } \\
(\%)\end{array}$ & $\begin{array}{c}\text { Açúcar } \\
(\%)\end{array}$ & $\begin{array}{c}\text { Aspartame } \\
(\%)\end{array}$ & $\begin{array}{c}\text { Pectina ATM } \\
(\%)\end{array}$ & $\begin{array}{c}\text { Pectina BTM } \\
(\%)\end{array}$ & $\begin{array}{c}\text { Cloreto de cálcio } \\
(\%)\end{array}$ \\
\hline GC1 & 49,5 & 50,0 & - & 0,5 & - & - \\
\hline GC2 & 44,0 & 55,0 & - & 1,0 & - & - \\
\hline GD1 & 98,262 & - & 0,055 & - & 1,5 & $0,083^{*}$ \\
\hline GD2 & 98,242 & - & 0,075 & - & 1,5 & $0,083^{*}$ \\
\hline
\end{tabular}

GC - Geleia convencional; GD - Geleia dietética. ${ }^{*}$ Calculado a partir da quantidade de pectina utilizada.

As análises da composição nutricional foram realizadas no tempo inicial (após processamento) e a cada 30 dias de armazenamento. Foram realizadas as análises em triplicata de teor de água, cinzas, açúcares totais, açúcares redutores em glicose e não redutores em sacarose, segundo normas do Instituto Adolfo Lutz (IAL, 2008); proteínas (método de micro Kjeldahl) (AOAC, 2016); carboidratos totais (por diferença) e valor calórico (BRASIL, 2005).

O tratamento estatístico (ANOVA) dos dados foi realizado com auxílio do programa Assistat 7.7 Beta (SILVA, AZEVEDO, 2016), utilizando esquema fatorial, sendo a comparação de médias realizada pelo Teste de Tukey a 5\% de significância.

\section{Resultados e discussão}

A Tabela 2 aponta os teores de água das geleias convencionais e dietéticas de umbu-cajá, durante a estocagem. As geleias convencionais apresentaram teor de umidade intermediário, inferior a $45 \%$, diferindo estatisticamente $(p<0,05)$ das geleias dietéticas, que revelaram mais de $85 \%$ de umidade em sua composição, o que está relacionado à maior concentração ( ${ }^{\circ}$ Brix) final das geleias convencionais. Esses resultados são aproximados aos publicados por Souza et al. (2016), ao estudarem geleias convencionais de tamarindo, e Teles et al. (2017), que analisaram geleias de graviola, cujo teor de umidade foi de quase $40 \%$. Oliveira et al. (2015) também encontraram elevadas porcentagens de umidade ao estudarem geleias dietéticas de umbu-cajá, as quais apresentaram valores variando entre $87,72 \%$ e 89,54\%, durante seu armazenamento.

As geleias convencionais demostraram tendência significativa de redução do teor de umidade no decorrer da estocagem. Tal comportamento também foi verificado por Barcia et al. (2010), ao pesquisarem a estabilidade de geleias convencionais de jambolão. Os citados autores também reportaram redução significativa do teor de umidade nas geleias, com o armazenamento. Em relação às geleias dietéticas, o teor de umidade manteve-se estável durante a estocagem. Em estudo similar, Broomes e Badrie (2010) também reportaram estabilidade do teor de umidade em geleias dietéticas de hibisco, estocadas em condições ambientais. Oliveira et al. (2014) também reportam redução nos teores de umidade durante a estocagem, à temperatura ambiente, de geleias tradicionais de umbu-cajá elaboradas com sacarose.

Os maiores conteúdos de cinza (Tabela 3) foram encontrados nas geleias dietéticas, diferindo estatisticamente dos teores de cinzas das geleias convencionais. Esses resultados estão relacionados à maior porcentagem de polpa adicionada nas formulações durante o processamento das geleias dietéticas (Tabela 1). Como o açúcar cristal é um ingrediente saturado em sacarose e, de modo geral, as frutas são ricas do ponto de vista nutricional, com considerável conteúdo mineral, as formulações de geleias com os maiores teores de polpa apresentam, em consequência, os maiores conteúdos de cinzas. Yuyama et al. (2008) desenvolveram geleias convencionais e dietéticas de cubiu, e Nachtigall et al. (2004) elaboraram geleias convencionais e lights de hibisco, também constatando maior conteúdo mineral na geleia de baixo valor calórico.

O conteúdo de cinzas oscilou durante toda a estocagem das geleias (Tabela 3), mantendo-se estável ao final da estocagem, apesar da tendência não significativa de concentração mineral na maioria das amostras. Nachtigall et al. (2004) estudaram a estabilidade de geleias de hibisco armazenadas em condições ambientais por 180 dias e reportaram estabilidade do conteúdo mineral, estando em acordo com os resultados da presente pesquisa.

Assim como verificado para cinzas, o conteúdo proteico foi maior nas geleias dietéticas, em comparação às geleias convencionais (Tabela 4), com diferença estatística entre os dois tipos de geleias (convencional e dietética), o que se pode relacionar à maior porcentagem de polpa adicionada nas geleias dietéticas durante a formulação. Observações similares foram relatadas por Barcia et al. (2010), ao estudarem geleias de jambolão, também reportando maiores teores de proteínas para as formulações de baixo valor calórico (light), em comparação com as formulações convencionais, corroborando com os dados encontrados no presente estudo. Santos et al. (2014), ao estudarem a composição nutricional de geleias convencionais de abacaxi, encontraram valores de proteínas $(0,77 \%$ a $0,79 \%)$ superiores aos do presente estudo para as geleias convencionais, mas inferiores aos das geleias diet. 
Tabela 2. Teor de umidade (\%) das geleias durante estocagem em condições ambientais.

\begin{tabular}{cccccccc} 
Geleia & \multicolumn{7}{c}{ Estocagem (dias) - Umidade (\%) } \\
\cline { 2 - 8 } GC1 & $\mathbf{0}$ & $\mathbf{3 0}$ & $\mathbf{6 0}$ & $\mathbf{9 0}$ & $\mathbf{1 2 0}$ & $\mathbf{1 5 0}$ \\
GC2 & $42,42^{\mathrm{bA}}$ & $40,76^{\mathrm{bB}}$ & $40,34^{\mathrm{bBC}}$ & $39,13^{\mathrm{bCDE}}$ & $39,66^{\mathrm{bBCD}}$ & $38,28^{\mathrm{bDE}}$ & $37,87^{\mathrm{bE}}$ \\
GD1 & $38,43^{\mathrm{CA}}$ & $37,37^{\mathrm{CAB}}$ & $37,10^{\mathrm{AAB}}$ & $37,25^{\mathrm{CAB}}$ & $36,87^{\mathrm{CAB}}$ & $36,49^{\mathrm{cB}}$ & $36,52^{\mathrm{bB}}$ \\
GD2 & $87,94^{\mathrm{aA}}$ & $88,77^{\mathrm{aA}}$ & $88,44^{\mathrm{aA}}$ & $88,54^{\mathrm{aA}}$ & $88,16^{\mathrm{aA}}$ & $88,07^{\mathrm{aA}}$ & $88,65^{\mathrm{aA}}$ \\
\hline
\end{tabular}

GC - Geleia convencional; GD - Geleia dietética; Média geral =63,66\%; Coeficiente de variação = 1,01; Desvio mínimo significativo para colunas =1,389; Desvio mínimo significativo para linhas = 1,60. Médias com mesma letra minúscula na coluna e maiúscula na linha não apresentam diferença significativa entre si. Foi aplicado o Teste Tukey para diferença de médias a 5\% de significância.

Tabela 3. Teor de cinzas (\%) das geleias durante estocagem em condições ambientais.

\begin{tabular}{cccccccc} 
Geleia & $\mathbf{7}$ & \multicolumn{7}{c}{ Estocagem (dias) - Cinzas (\%) } \\
\cline { 2 - 8 } & $\mathbf{0}$ & $\mathbf{3 0}$ & $\mathbf{6 0}$ & $\mathbf{9 0}$ & $\mathbf{1 2 0}$ & $\mathbf{1 5 0}$ & $\mathbf{1 8 0}$ \\
GC1 & $0,18^{\mathrm{bA}}$ & $0,23^{\mathrm{bA}}$ & $0,22^{\mathrm{bA}}$ & $0,27^{\mathrm{bA}}$ & $0,28^{\mathrm{bA}}$ & $0,29^{\mathrm{bA}}$ & $0,26^{\mathrm{bA}}$ \\
GC2 & $0,23^{\mathrm{bA}}$ & $0,26^{\mathrm{bA}}$ & $0,25^{\mathrm{bA}}$ & $0,25^{\mathrm{bA}}$ & $0,25^{\mathrm{bA}}$ & $0,27^{\mathrm{bA}}$ & $0,25^{\mathrm{bA}}$ \\
GD1 & $0,81^{\mathrm{aA}}$ & $0,79^{\mathrm{aA}}$ & $0,90^{\mathrm{aA}}$ & $0,92^{\mathrm{aA}}$ & $0,90^{\mathrm{aA}}$ & $0,93^{\mathrm{aA}}$ & $0,87^{\mathrm{aA}}$ \\
GD2 & $0,78^{\mathrm{aA}}$ & $0,77^{\mathrm{aA}}$ & $0,83^{\mathrm{aA}}$ & $0,85^{\mathrm{aA}}$ & $0,82^{\mathrm{aA}}$ & $0,89^{\mathrm{aA}}$ & $0,72^{\mathrm{aA}}$ \\
\hline
\end{tabular}

GC - Geleia convencional; GD - Geleia dietética; Média geral =0,54\%; Coeficiente de variação = 14,37\%; Desvio mínimo significativo para colunas $=0,17$; Desvio mínimo significativo para linhas $=0,19$. Médias com mesma letra minúscula na coluna e maiúscula na linha não apresentam diferença significativa entre si. Foi aplicado o Teste Tukey para diferença de médias a 5\% de significância.

Tabela 4. Teor de proteínas (\%) das geleias durante estocagem em condições ambientais.

\begin{tabular}{cccccccc} 
Geleia & \multicolumn{7}{c}{ Estocagem (dias) - Proteínas (\%) } \\
\cline { 2 - 8 } GC1 & $\mathbf{0}$ & $\mathbf{3 0}$ & $\mathbf{6 0}$ & $\mathbf{9 0}$ & $\mathbf{1 2 0}$ & $\mathbf{1 5 0}$ & $\mathbf{1 8 0}$ \\
GC2 & $0,30^{\mathrm{bAB}}$ & $0,23^{\mathrm{bB}}$ & $0,36^{\mathrm{bA}}$ & $0,31^{\mathrm{bAB}}$ & $0,32^{\mathrm{bAB}}$ & $0,34^{\mathrm{bAB}}$ & $0,28^{\mathrm{bAB}}$ \\
GD1 & $0,26^{\mathrm{bA}}$ & $0,27^{\mathrm{bA}}$ & $0,33^{\mathrm{bA}}$ & $0,33^{\mathrm{bA}}$ & $0,33^{\mathrm{bA}}$ & $0,30^{\mathrm{bA}}$ & $0,27^{\mathrm{bA}}$ \\
GD2 & $1,03^{\mathrm{aAB}}$ & $0,97^{\mathrm{aB}}$ & $1,14^{\mathrm{aA}}$ & $1,02^{\mathrm{aAB}}$ & $1,06^{\mathrm{aAB}}$ & $1,01^{\mathrm{aAB}}$ & $0,99^{\mathrm{aB}}$ \\
\hline
\end{tabular}

GC - Geleia convencional; GD - Geleia dietética; Média geral =0,66\%; Coeficiente de variação = 7,89\%; Desvio mínimo significativo para colunas $=0,11$; Desvio mínimo significativo para linhas $=0,13$. Médias com mesma letra minúscula na coluna e maiúscula na linha não apresentam diferença significativa entre si. Foi aplicado o Teste Tukey para diferença de médias a 5\% de significância.

Tabela 5. Teor de carboidratos (\%) das geleias durante estocagem em condições ambientais.

\begin{tabular}{cccccccc} 
Geleia & \multicolumn{7}{c}{ Estocagem (dias) - Carboidratos totais (\%) } \\
\cline { 2 - 7 } & $\mathbf{0}$ & $\mathbf{3 0}$ & $\mathbf{6 0}$ & $\mathbf{9 0}$ & $\mathbf{1 2 0}$ & $\mathbf{1 5 0}$ & $\mathbf{1 8 0}$ \\
GC1 & $57,09^{\mathrm{bE}}$ & $57,76^{\mathrm{bDE}}$ & $59,08^{\mathrm{bCD}}$ & $60,29^{\mathrm{bABC}}$ & $59,75^{\mathrm{bBC}}$ & $61,09^{\mathrm{bAB}}$ & $61,59^{\mathrm{aA}}$ \\
GC2 & $61,08^{\mathrm{aB}}$ & $62,10^{\mathrm{aAB}}$ & $62,42^{\mathrm{aAB}}$ & $62,18^{\mathrm{aAB}}$ & $62,56^{\mathrm{aAB}}$ & $62,94^{\mathrm{aA}}$ & $62,96^{\mathrm{aA}}$ \\
GD1 & $10,21^{\mathrm{CA}}$ & $9,42^{\mathrm{CA}}$ & $9,40^{\mathrm{cA}}$ & $9,52^{\mathrm{cA}}$ & $9,88^{\mathrm{cA}}$ & $10,00^{\mathrm{cA}}$ & $9,49^{\mathrm{bA}}$ \\
GD2 & $9,14^{\mathrm{CA}}$ & $8,95^{\mathrm{cA}}$ & $8,77^{\mathrm{cA}}$ & $8,65^{\mathrm{cA}}$ & $8,84^{\mathrm{cA}}$ & $8,80^{\mathrm{cA}}$ & $8,82^{\mathrm{bA}}$ \\
\hline
\end{tabular}

GC - Geleia convencional; GD - Geleia dietética: Média geral = 35,10\%: Coeficiente de variação = 1,97\%: Desvio mínimo significativo para colunas $=1,50$; Desvio mínimo significativo para linhas $=1,73$. Médias com mesma letra minúscula na coluna e maiúscula na linha não apresentam diferença significativa entre si. Foi aplicado o Teste Tukey para diferença de médias a $5 \%$ de significância.

Os teores de proteínas se mantiveram estáveis em praticamente todos os tempos de armazenagem de todas as geleias (Tabela 4). No entanto, constatou-se disposição à redução desses valores nas formulações GC1, GD1 e GD2, mas não significativa. Celestino (2013), ao estudar geleia convencional de buriti, reporta variações nos teores de proteínas durante a armazenagem de 0,17\% (tempo zero) a 0,21\% (90 dias de armazenamento), com oscilações durante o período.

Os maiores teores de carboidratos foram encontrados nas geleias convencionais (Tabela 5), com diferença significativa quando comparados aos valores das geleias dietéticas. Esses resultados já eram esperados, uma vez que, nas geleias convencionais, foi utilizada mais de $50 \%$ de sacarose, enquanto que, nas formulações diet, a sacarose foi substituída por aspartame. Yuyama et al. (2008), ao estudarem geleias de cubiu, e Barcia et al. (2010), ao trabalharem com geleias de jambolão, também reportaram maior conteúdo de carboidratos nas formulações de geleias convencionais.

Após 180 dias de armazenamento, verificou-se que os carboidratos totais sofreram um aumento estatisticamente 
significativo $(p<0,05)$ nas formulações convencionais (Tabela 5), em relação aos valores iniciais, correspondendo a aumentos de 7,88\% na amostra GC1 e 3,08\% na amostra GC2. Nas geleias dietéticas, constatou-se que os carboidratos permaneceram estatisticamente estáveis durante toda a estocagem. Esses resultados podem ser correlacionados com os teores de umidade, que tiveram tendência de redução e estabilidade nas geleias convencionais e dietéticas, respectivamente, durante o período de estocagem. Resultados semelhantes foram relatados por Damiani et al. (2012), ao estudarem geleias convencionais elaboradas com araçá. Os citados autores também reportaram elevações nos valores de carboidratos, ao final da estocagem. Nachtigall et al. (2004) verificaram redução no conteúdo de carboidratos durante os 180 dias de estocagem de geleias light de hibisco, elaboradas com acessulfame-K e sucralose.

As geleias convencionais apresentaram os maiores valores calóricos (Tabela 6), sendo que os resultados diferiram significativamente dos encontrados para as geleias dietéticas, as quais tiveram resultados inferiores a $50 \mathrm{kcal} / 100 \mathrm{~g}$, o que está relacionado aos maiores conteúdos de carboidratos nas amostras convencionais, proporcionados pela adição de sacarose, em relação às amostras dietéticas. Nos estudos de Barcia et al. (2010) e de Yuyama et al. (2008), também foram evidenciados maiores valores calóricos nas geleias convencionais, em comparação às formulações light ou diet.

Houve disposição com significância de elevação para os resultados de valor calórico durante os 180 dias de armazenamento das geleias elaboradas com sacarose, enquanto que as geleias elaboradas com aspartame demostraram estabilidade estatística para esse parâmetro durante a estocagem, apesar de ligeira redução das calorias, ao término da estocagem. Essa redução já era esperada, visto que, os carboidratos aumentaram nas geleias convencionais e houve tendência à estabilidade nas amostras dietéticas, durante a estocagem. Observação semelhante, com a elevação de calorias com a armazenagem, também foi apresentada por Damiani et al. (2012), ao estudarem a estabilidade de geleia convencional mista elaborada com araçá. No estudo de Nachtigall et al. (2004), sobre o armazenamento de geleias light de amora-preta, foi relatada redução nos valores calóricos das geleias durante $o$ armazenamento, se equiparando com os resultados obtidos no presente trabalho para as geleias dietéticas.

Verificou-se que as geleias convencionais apresentaram mais de $60 \%$ de açúcares totais (Tabela 7 ), diferindo significativamente $(p<0,05)$ das geleias dietéticas, que revelaram menos de $10 \%$ desse constituinte, uma vez que, nestas formulações, havia apenas os açúcares da própria fruta. Os estudos de Yuyama et al. (2008), que trabalharam com geleias dietéticas de cubiu, e de Prati et al. (2009), com geleias dietéticas mistas de acerola, goiaba e yacon, indicaram concentração de açúcares totais inferiores a 10\%. Damiani et al. (2012) reportaram, em geleias convencionais de araçá, conteúdos de açúcares totais superiores a $60 \%$, próximos aos do presente estudo.

Os açúcares totais apresentaram decréscimos significativos $(p<0,05)$, ao final dos 180 dias de armazenamento, nas geleias elaboradas com sacarose (Tabela 7), possivelmente devido à degradação de açúcares decorrente de reações de síntese de melanoidinas.

Tabela 6. Valor calórico das geleias durante estocagem em condições ambientais.

\begin{tabular}{cccccccc} 
Geleia & \multicolumn{7}{c}{ Estocagem (dias) - Valor calórico (kcal/100 g) } \\
\cline { 2 - 7 } & $\mathbf{0}$ & $\mathbf{3 0}$ & $\mathbf{6 0}$ & $\mathbf{9 0}$ & $\mathbf{1 2 0}$ & $\mathbf{1 5 0}$ & $\mathbf{1 8 0}$ \\
GC1 & $229,57^{\mathrm{bE}}$ & $231,94^{\mathrm{bDE}}$ & $237,75^{\mathrm{bCD}}$ & $242,39^{\mathrm{bABC}}$ & $240,26^{\mathrm{bBC}}$ & $245,74^{\mathrm{bAB}}$ & $247,46^{\mathrm{aA}}$ \\
GC2 & $245,37^{\mathrm{aB}}$ & $249,48^{\mathrm{aAB}}$ & $250,99^{\mathrm{aAB}}$ & $250,01^{\mathrm{aAB}}$ & $251,54^{\mathrm{AB}}$ & $252,97^{\mathrm{aA}}$ & $252,92^{\mathrm{aA}}$ \\
GD1 & $44,98^{\mathrm{cA}}$ & $41,56^{\mathrm{cA}}$ & $42,14^{\mathrm{CA}}$ & $42,18^{\mathrm{cA}}$ & $43,76^{\mathrm{cA}}$ & $44,04^{\mathrm{CA}}$ & $41,91^{\mathrm{bA}}$ \\
GD2 & $40,71^{\mathrm{cA}}$ & $39,56^{\mathrm{cA}}$ & $39,29^{\mathrm{cA}}$ & $38,49^{\mathrm{cA}}$ & $39,44^{\mathrm{cA}}$ & $39,04^{\mathrm{cA}}$ & $38,97^{\mathrm{bA}}$ \\
\hline
\end{tabular}

GC - Geleia convencional; GD - Geleia dietética; Média geral = 143,02 kcal/100 g: Coeficiente de variação = 1,91\%; Desvio mínimo significativo para colunas $=5,91$; Desvio mínimo significativo para linhas $=6,82$. Médias com mesma letra minúscula na coluna e maiúscula na linha não apresentam diferença significativa entre si. Foi aplicado o Teste Tukey para diferença de médias a $5 \%$ de significância.

Tabela 7. Teor de açúcares totais (\%) das geleias durante estocagem em condições ambientais.

\begin{tabular}{cccccccc} 
Geleia & \multicolumn{7}{c}{ Estocagem (dias) - Açúcares totais (\%) } \\
\cline { 2 - 7 } & $\mathbf{0}$ & $\mathbf{3 0}$ & $\mathbf{6 0}$ & $\mathbf{9 0}$ & $\mathbf{1 2 0}$ & $\mathbf{1 5 0}$ & $\mathbf{1 8 0}$ \\
GC1 & $66,98^{\mathrm{aA}}$ & $62,34^{\mathrm{bB}}$ & $63,33^{\mathrm{bB}}$ & $51,57^{\mathrm{bD}}$ & $53,80^{\mathrm{bCD}}$ & $52,97^{\mathrm{bD}}$ & $56,02^{\mathrm{aC}}$ \\
GC2 & $64,60^{\mathrm{bB}}$ & $65,60^{\mathrm{aAB}}$ & $67,26^{\mathrm{aA}}$ & $54,40^{\mathrm{aD}}$ & $57,92^{\mathrm{aC}}$ & $56,53^{\mathrm{aCD}}$ & $56,00^{\mathrm{aCD}}$ \\
GD1 & $8,34^{\mathrm{cA}}$ & $8,10^{\mathrm{cA}}$ & $8,44^{\mathrm{CA}}$ & $7,43^{\mathrm{cA}}$ & $7,53^{\mathrm{cA}}$ & $7,03^{\mathrm{cA}}$ & $7,47^{\mathrm{bA}}$ \\
GD2 & $7,93^{\mathrm{cA}}$ & $7,36^{\mathrm{cA}}$ & $7,47^{\mathrm{cA}}$ & $6,26^{\mathrm{cA}}$ & $6,14^{\mathrm{cA}}$ & $6,65^{\mathrm{cA}}$ & $6,87^{\mathrm{bA}}$ \\
\hline
\end{tabular}

GC - Geleia convencional; GD - Geleia dietética; Média geral = 33,30\%; Coeficiente de variação = 2,87\%; Desvio mínimo significativo para colunas $=2,07$; Desvio mínimo significativo para linhas $=2,38$. Médias com mesma letra minúscula na coluna e maiúscula na linha não apresentam diferença significativa entre si. Foi aplicado o Teste Tukey para diferença de médias a 5\% de significância. 
Tabela 8. Teor de açúcares redutores e não redutores (\%) das geleias durante estocagem em condições ambientais.

\begin{tabular}{|c|c|c|c|c|c|c|c|}
\hline \multirow{2}{*}{ Geleia } & \multicolumn{7}{|c|}{ Estocagem (dias) - Açúcares redutores (\%) } \\
\hline & 0 & 30 & 60 & 90 & 120 & 150 & 180 \\
\hline GC1 & $36,40^{\mathrm{aE}}$ & $43,67^{\mathrm{aD}}$ & $48,03^{\mathrm{ac}}$ & $48,92^{\mathrm{aC}}$ & $51,50^{\mathrm{aB}}$ & $49,03^{\mathrm{ac}}$ & $54,42^{\mathrm{aA}}$ \\
\hline GC2 & $27,37^{\mathrm{bE}}$ & $37,04^{\mathrm{bD}}$ & $40,11^{\mathrm{bc}}$ & $37,07^{\mathrm{bD}}$ & $42,28^{\mathrm{bBC}}$ & $44,28^{\mathrm{bB}}$ & $49,49^{\mathrm{bA}}$ \\
\hline \multirow{2}{*}{ Geleia } & \multicolumn{7}{|c|}{ Estocagem (dias) - Açúcares não redutores (\%) } \\
\hline & 0 & 30 & 60 & 90 & 120 & 150 & 180 \\
\hline GC1 & $29,05^{\mathrm{bA}}$ & $17,74^{\mathrm{bB}}$ & $14,53^{\mathrm{bB}}$ & $2,52^{\mathrm{bC}}$ & $2,19^{\mathrm{bC}}$ & $3,75^{b c}$ & $1,52^{\mathrm{bc}}$ \\
\hline GC2 & $35,37^{\mathrm{aA}}$ & $27,13^{\mathrm{aB}}$ & $25,79^{a B}$ & $16,46^{\mathrm{ac}}$ & $14,86^{\mathrm{aCD}}$ & $11,63^{\mathrm{aD}}$ & $6,19^{\mathrm{aE}}$ \\
\hline
\end{tabular}

GC - Geleia convencional; Média geral açúcares redutores = 43,54\%; Média geral açúcares não redutores = 14,91\%; Coeficiente de variação açúcares redutores = 2,04\%; Coeficiente de variação açúcares não redutores = 9,08\%; Desvio mínimo significativo para colunas açúcares redutores $=1,49$. Desvio mínimo significativo para colunas acúcares não redutores $=2,27$; Desvio mínimo significativo para linhas accúcares redutores $=2,30$; Desvio mínimo significativo para linhas açúcares não redutores $=3,50$. Médias com mesma letra minúscula na coluna e maiúscula na linha não apresentam diferença significativa entre si. Foi aplicado o Teste Tukey para diferença de médias a $5 \%$ de significância. Análise estatística aplicada individualmente para cada parâmetro avaliado.

Reduções dos açúcares totais são mencionadas por Safdar et al. (2012) e Chauhan et al. (2012), ao estudarem geleias convencionais de manga e coco, respectivamente. Em relação às geleias dietéticas, observou-se que os açúcares totais apresentaram tendência a estabilidade, apesar de pequena redução nesses valores ao final da armazenagem, em comparação aos teores iniciais. Os resultados encontrados apresentaram o mesmo comportamento dos reportados por Barcia et al. (2010), ao trabalharem com geleias de jambolão armazenadas em temperatura ambiente, nas quais os autores relatam que houve menor degradação dos açúcares nas geleias de baixo valor calórico, quando comparadas com as convencionais.

A amostra GC1 evidenciou os maiores valores para açúcares redutores e menores para açúcares não redutores, ambos diferindo estatisticamente $(p<0,05)$ da amostra GC2 (Tabela 8). Como a formulação GC1 continha menor quantidade de sacarose (Tabela 1), esta necessitou de maior tempo de aquecimento e concentração dos sólidos solúveis totais até aproximadamente $63^{\circ}$ Brix, o que favoreceu a maior hidrólise da sacarose pelo calor. Essas observações são sustentadas por Nachtigall et al. (2004), que afirmam que a maior proporção de açúcares redutores em geleias indica maior hidrólise ocasionada pelo aquecimento na etapa de cocção.

Os 180 dias de armazenamento das geleias convencionais favoreceram a ocorrência de aumentos significativos nos teores de açúcares redutores e reduções significativas nos valores de açúcares não redutores (Tabela 8). Esses resultados possivelmente são decorrentes da hidrólise da sacarose no decorrer da estocagem, levando à formação de glicídios redutores (frutose e glicose), o que pode estar relacionado com reações provocadas por ácidos orgânicos, como o ácido cítrico, como cita Yuyama et al. (2008), visto que os açúcares não redutores, a exemplo da sacarose, são hidrolisados em meio ácido.

Comportamento semelhante, com redução dos açúcares não redutores e aumento dos açúcares redutores, também é reportado por Martins et al. (2015), ao pesquisarem a estabilidade de geleias convencionais de cajá, e por Arévalo-Pinedo et al. (2013), em geleias convencionais e light de araticum. Esses autores também verificaram elevações nos valores de açúcares redutores, ao final do armazenamento.

Não foram encontrados valores quantificáveis de açúcares redutores e não redutores nas geleias dietéticas.

\section{Conclusão}

As geleias dietéticas revelaram as maiores porcentagens de água, proteínas e cinzas, e os menores teores de carboidratos e açúcares totais, diferindo das geleias convencionais, que apresentaram maiores conteúdos de açúcares e carboidratos totais, e redução de cinzas e proteínas. Os valores calóricos das geleias convencionais foram mais de cinco vezes superiores, em comparação às amostras dietéticas.

Os produtos elaborados com aspartame revelaram boa estabilidade nutricional no decorrer dos 180 dias de estocagem, com estabilidade estatística dos valores de teor de umidade, proteínas, cinzas, açúcares totais, carboidratos e calorias.

O armazenamento das geleias convencionais promoveu aumentos significativos nos teores de carboidratos, calorias e açúcares redutores, e redução nos resultados de teor de umidade, açúcares (totais e não redutores), diversamente das cinzas e proteínas, que permaneceram estáveis no decorrer do armazenamento.

\section{Referências}

ARÉVALO-PINEDO, A.; CARNEIRO, B. L. A.; ZUNIGA, A. D. G.; ARÉVALO, Z. D. S.; SANTANA, A. A.; PINEDO, R. A. alterações físico-químicas e colorimétricas de geleias de araticum (Annona crassiflora). Revista Brasileira de Produtos Agroindustriais, v. 15, n. 4, p. 397-403, 2013. http://dx.doi.org/10.15871/15178595/rbpa.v15n4p397-403. 
Composição nutricional de geleias de Umbu-Cajá durante estocagem em temperatura ambiente Oliveira, E. N. A. et al.

ASSOCIATION OF OFFICIAL ANALYTICAL CHEMISTS - AOAC. Official Methods of Analysis. 20th ed. Washington: AOAC, 2016. p. 3172

BARCIA, M. T.; MEDINA, A. L.; ZAMBIAZI, R. C. Características físico-químicas e sensoriais de geleia de jambolão. Boletim do Centro de Pesquisa e Processamento de Alimentos, v. 28, n. 1, p. 25-36, 2010. http://dx.doi.org/10.5380/cep.v28i1.17894.

BRASIL. Ministério da Saúde. RDC 12 de 24 de Julho de 1978. Estabelece normas técnicas relativas a alimentos e bebidas. Diário Oficial [da] Republica Federativa do Brasil, Brasília, DF, 24 jun. 1978

BRASIL. Ministério da Saúde. Agência Nacional de Vigilância Sanitária. Rotulagem nutricional obrigatória: manual de orientação às indústrias de Alimentos. Versão 2. Brasília: Universidade de Brasília, 2005. $44 \mathrm{p}$

BRASIL. Ministério da Saúde. RDC 18 de 24 de março de 2008. Estabelece regulamento técnico para uso de aditivos e edulcorantes em alimentos. Diário Oficial [da] Republica Federativa do Brasil, Brasília, DF, 25 mar. 2008.

BRASIL. Ministério da Saúde. RDC 28 de 26 de maio de 2009. Define a atribuição de aditivos alimentares, suas funções e seus limites máximos para geleias. Diário Oficial [da] Republica Federativa do Brasil, Brasília, DF, 27 maio 2009.

BROOMES, J.; BADRIE, N. Effects of low-methoxyl pectin on physicochemical and sensory properties of reduced- calorie sorrel/roselle (Hibiscus sabdariffa L.) jams. The Open Food Science Journal, v. 4, p.48-55, 2010.

CARDELLO, H. M. A. B.; SILVA, M. A. A. P.; DAMÁSIO, M. H. Descriptive quantitative analysis of sweeteners in differents concentrations. Food Science and Technology, v. 20, n. 3, p. 318-328, 2000. http://dx.doi.org/10.1590/S0101-20612000000300008.

CARneIRo, L. M.; PIRES, C. R. F.; LIMA, J. P.; PEREIRA, P. A. P.; LIMA, L. C. O. Evaluation of stability of blackberry jams conditioned in different packaging materials. Journal of Bioenergy and Food Science, v. 3, n. 2, p. 89-102, 2016. http://dx.doi. org/10.18067/jbfs.v3i2.99.

CELESTINO, S. M. C. Desenvolvimento e avaliação da vidase-prateleira de geleia de buriti. Boletim de Pesquisa e Desenvolvimento, v. 313, p. 1-27, 2013.

CHAUHAN, O. P.; ARCHANA, B. S.; SINGH, A.; RAJU, P. S.; BAWA, A. S. Utilization of tender coconut pulp for jam making and its quality evaluation during storage. Food and Bioprocess Technology, v. 5, n. 6, p. 1-8, 2012.

DAMIANI, C.; ASQUIERI, E. R.; LAGE, M. E.; OLIVEIRA, R. A.; SILVA, F. A.; PEREIRA, D. E. P.; VILAS BOAS, E. V. B. Study of the shelf-life of a mixed araça (Psidium guineensis Sw.) and marolo (Annona crassiflora Mart.) jam. Food Science and Technology, v. 32, n. 2, p. 334-343, 2012. http://dx.doi.org/10.1590/S010120612012005000050.
FURLANETO, K. A.; RAMOS, J. A.; DAIUTO, A. R.; VIEITES, R. L.; CARVALHO, L. R. Elaboração e aceitabilidade da geleia convencional e light de maná cubiu. Nativa (Sinop), v. 3, n. 4, p. 276-280, 2015. http://dx.doi.org/10.14583/2318-7670.v03n04a09.

INSTITUTO ADOLFO LUTZ - IAL. Normas analíticas, métodos químicos e físicos para análises de alimentos. 4. ed., 1. ed. São Paulo: Digital, 2008. p 1020.

LIMA, E. D. P. A.; LIMA, C. A. A.; ALDRIGUE, M. L.; GONDIM, P. J. S. Caracterização física e química dos frutos da umbucajazeira (Spondias spp) em cinco estádios de maturação, da polpa congelada e néctar. Revista Brasileira de Fruticultura, v. 24, n. 2, p. 338-343, 2002. http://dx.doi.org/10.1590/S010029452002000200013.

MARTINS, J. J. A.; OLIVEIRA, E. N. A.; ROCHA, A. P. T.; SANTOS, D. C. Estabilidade das geléias de cajá durante o armazenamento em condições ambientais. Comunicata Scientiae, v. 6, n. 2, p. 164-173, 2015.

MESQUITA, K. S.; BORGES, S. V.; CARNEIRO, J. D. S.; MENEZES, C. C.; MARQUES, G. R. Quality alterations during storage of sugar-free guava jam with added prebiotics. Journal of Food Processing and Preservation, v. 37, n. 5, p. 806-813, 2013. http://dx.doi.org/10.1111/j.1745-4549.2012.00703.x.

MONTEIRO, D. C. B.; PIRES, C. R. F. Avaliação da estabilidade físico-química de geleias de murici armazenadas sob diferentes condições de temperatura e luminosidade. Revista Desafios, v. 3, n. Especial, p. 87-98, 2016.

NACHTIGALL, A. M.; ZAMBIAZI, R. C.; CARVALHO, D. S. Geleia light de hibisco: características físicas e químicas. Revista Alimentos \& Nutrição, v. 15, n. 2, p. 155-161, 2004

NGOUÉMAZONG, D. E.; TENGWEH, F. F.; FRAEYE, I.; DUVETTER, T.; CARDINAELS, R.; VAN LOEY, A.; MOLDENAERS, P.; HENDRICKX, $M$. Effect of de-methylesterification on network development and nature of $\mathrm{Ca}^{2+}$-pectin gels: toward understanding structurefunction relations of pectin. Food Hydrocolloids, v. 26, n. 1, p. 89-98, 2012. http://dx.doi.org/10.1016/j.foodhyd.2011.04.002.

OLIVEIRA, E. N. A.; SANTOS, D. C.; GOMES, J. P.; ROCHA, A. P. T.; SILVA, W. P. Physicochemical stability of diet umbu-caja jams stored under ambient conditions. Journal of Food Processing and Preservation, v. 39, n. 1, p. 70-79, 2015. http://dx.doi. org/10.1111/jfpp. 12209.

OLIVEIRA, E. N. A.; SANTOS, D. C.; ROCHA, A. P. T.; GOMES, J. P.; SILVA, W. P. Estabilidade de geleias convencionais de umbu-cajá durante o armazenamento em condições ambientais. Revista Brasileira de Engenharia Agrícola e Ambiental, v. 18, n. 3, p. 329-337, 2014. http://dx.doi.org/10.1590/S141543662014000300013.

PAIVA, C. A.; AROUCHA, E. M. M.; FERREIRA, R. M. A.; ARAÚJO, N. O.; SILVA, P. S. L. Alterações físico-químicas de geleias de melão e acerola durante o armazenamento. Revista Verde, v. 10, n. 3, p. 18-23, 2015. http://dx.doi.org/10.18378/rvads.v10i3.3495. 
Composição nutricional de geleias de Umbu-Cajá durante estocagem em temperatura ambiente

Oliveira, E. N. A. et al.

PRATI, P.; BERBARI, S. A. G.; PACHECO, M. T. B.; SILVA, M. G.; NACAZUME, N. Estabilidade dos componentes funcionais de geleia de yacon, goiaba e acerola, sem adição de açúcares. Brazilian Journal of Food Technology, v. 12, n. 4, p. 285-294, 2009. http://dx.doi.org/10.4260/BJFT2009800900023.

SAFDAR, M. N.; MUMTAZ, A.; HAMEED, T.; SIDDIQUI, N.; KHALIL, S.; AMJAD, M. Storage studies of jam prepared from different mango varieties. Pakistan Journal of Nutrition, v. 11, n. 7 , p. 555-561, 2012. http://dx.doi.org/10.3923/pjn.2012.653.659.

SANTOS, K. A.; FAIX, P. N.; SANTOS, E. F.; MANHANI, M. R.; SILVA, E. C.; NOVELLO, D. Efeito da adição de inulina em geleia de abacaxi: análise físico-química e sensorial entre escolares. O Mundo da Saúde, v. 38, n. 3, p. 286-295, 2014.

SILVA, F. A. Z.; AZEVEDO, C. A. V. The assistat software version 7.7 and its use in the analysis of experimental data. African
Journal of Agricultural Research, v. 11, n. 39, p. 3733-3740, 2016. http://dx.doi.org/10.5897/AJAR2016.11522.

SOUZA, F. G.; BARBOSA, F. F.; RODRIGUES, F. M. Evaluation of tamarind jelly without pectin and pectin from the albedo of yellow passion fruit. Journal of Bioenergy and Food Science, v. 3, n. 2, p. 78-88, 2016. http://dx.doi.org/10.18067/jbfs.v3i2.52.

TELES, A. C. M.; PINTO, E. G.; SANTOS, J. R.; OLIVEIRA, C. F. D.; SOARES, D. S. B. Desenvolvimento e caracterização físicoquímica de geleia comum e extra de graviola com pimenta. Revista de Agricultura Neotropical, v. 4, n. 1, p. 72-77, 2017. YUYAMA, L. K. O.; PANTOJA, L.; MAEDA, R. N.; AGUIAR, J. P. L.; SILVA, S. B. Desenvolvimento e aceitabilidade de geleia dietética de cubiu (Solanum sessiliflorum Dunal). Food Science and Technology (Campinas), v. 28, n. 4, p. 929-934, 2008. http:// dx.doi.org/10.1590/S0101-20612008000400026. 